S.Ü. Müh. Bilim ve Tekn. Derg., c.6, s.3, ss. 355-376, 2018

\title{
AN AUTOMATED COMPUTER-AIDED DETECTION (CADe) AND DIAGNOSIS (CADx) SYSTEM FOR BREAST MICROCALCIFICATIONS IN MAMMOGRAMS
}

\author{
${ }^{1}$ Burçin KURT, ${ }^{2}$ Vasif V. NABIYYEV, ${ }^{3}$ Kemal TURHAN \\ 1,3 Karadeniz Technical University, Faculty of Medicine, Medical Informatics, Trabzon, Turkey \\ ${ }^{2}$ Karadeniz Technical University, Engineering Faculty, Computer Engineering, Trabzon, TURKEY \\ 1burcinnkurt@gmail.com, ${ }^{2}$ vasif@ktu.edu.tr, ${ }^{3}$ kturhan.tr@gmail.com
}

(Geliş/Received: 10.03.2017; Kabul/Accepted in Revised Form: 30.11.2017)

\begin{abstract}
An automated computer aided diagnosis system has been proposed for detection of microcalcification (MC) clusters in mammograms. The proposed system is a whole system including suspicious regions identification, MCs detection, false positive reduction and benign/malign classification. For classification of suspicious microcalcification regions, a multilayer perceptron (MLP) neural network was used with grey level co-occurrence matrix (GLCM) and statistical features. Then to decrease the false positive classification ratio, we used cascade correlation neural network (CCNN) with grey level run length matrix (GLRLM) features. In the last step, hybrid form of discriminant analysis and support vector machine (SVM) methods were used with GLRLM features for benign/malign classification of detected MC clusters. The open access Mammographic Image Analysis Society (MIAS) database was used for the study. Experimental results show that the proposed algorithm obtained $86 \%$ sensitivity, $98.3 \%$ specificity and $1.163 \mathrm{FPpI}$ rates for detection an for diagnosis of breast cancer, the obtained sensitivity and specificity values are $100 \%$ and $100 \%$ respectively. Despite the vision difficulty of MC clusters, the novel system provides very satisfactory results. Furthermore, the developed system is fully automatic whole system which gives outputs as percentages and transformed assessment categories.
\end{abstract}

Key Words: Breast cancer, Computer aided diagnosis, Cascade correlation neural network (CCNN), Grey level cooccurrence matrix (GLCM), Grey level run length matrix (GLRLM), Mammograms.

\section{Mamografide Meme Mikrokalsifikasyonları için Otomatik Bilgisayar Destekli Tespit (CADe) ve Tanı (CADx) Sistemi}

ÖZ: Mamografide mikrokalsifikasyon (MC) kümelerinin saptanması için otomatik bir bilgisayar destekli tanı sistemi önerilmiştir. Önerilen sistem şüpheli bölgelerin tanımlanması, MC'lerin tespiti, yanlış pozitif indirgeme ve iyi huylu/kötü huylu sınıflamayı içeren bütün bir sistemdir. Şüpheli mikrokalsifikasyon bölgelerinin sınıflandırılması için, gri seviye eş-oluşum matrisi (GLCM) ve istatistiksel özellikler ile çok tabakalı bir perceptron (MLP) sinir ağı kullanıldı. Daha sonra, yanlış pozitif sınıflandırma oranını azaltmak için, gri seviye çalışma uzunluğu matrisi (GLRLM) özellikli kademeli korelasyon sinir ağı (CCNN) kullanılmıştır. Son adımda, tespit edilen MC kümelerinin iyi huylu/kötü huylu sınıflandırması için GLRLM özellikleri ile hibrid yapıda diskriminant analizi ve destek vektör makinesi (SVM) yöntemleri kullanıldı. Çalışma için açık erişimli Mamografik Görüntü Analizi Derneği (MIAS) veri tabanı kullanılmıştır. Deneysel sonuçlar, önerilen algoritmanın meme kanseri tespiti için \%86 duyarlılık, \%98.3 özgüllük ve 1.163 FPpI oranları elde ettiğini ve meme kanseri tanısı için elde edilen duyarlılık ve özgüllük değerlerinin sırasıyla \%100 ve \%100 olduğunu ortaya koymuştur. MC kümelenmelerinin görme zorluğu olsa da, önerilen sistem çok tatmin edici sonuçlar vermektedir. Bununla birlikte, gelişmiş sistem; çıtıları yüzdeler ve dönüştürülmüş değerlendirme kategorileri olarak veren tam otomatik bir bütün sistemdir. 
Anahtar Kelimeler: Meme kanseri, Bilgisayar destekli tanı, Kademeli korelasyon sinir ağı (CCNN), Gri seviye eşoluşu matrisi (GLCM), Gri seviye çalışma uzunluğu matrisi (GLRLM), Mamografi.

\section{INTRODUCTION}

Breast cancer is the leading cancer in women, including 25\% of all cancer cases (Stewart et al., 2014). Early diagnosis is very important for survival rate. Microcalcifications (MCs) are one of the most important abnormalities and can be defined as an early sign of breast cancer (Cheng et al., 2006). MCs are the calcium stores in the breast tissue and their sizes change between $0.1 \mathrm{~mm}$ and $1 \mathrm{~mm}$. Detection of MCs is a complex work because they appear as thin and bright spots. However, about $10 \%-40 \%$ of MC clusters are missed by radiologists because of their small sizes (Bird et al., 1992). Detection of them can increase the treatment options and survival rates. Therefore, computer-aided detection/diagnosis (CAD) systems are developed to assist radiologists to interpret and diagnose mammograms.

(Martins et al., 2006) extracted the grey level co-occurrence matrix (GLCM) features such as contrast, homogeneity, inverse difference moment, entropy and energy texture features for classification of suspicious MC regions. Then, these regions were classified as normal, benign and malign using Bayesian neural network (BNN). But the success of benign classification result is low.

(Phadke et al., 2013) presented an approach for detection and classification of microcalcifications in digital mammograms. Region of interest (ROI) has been cropped from the original mammogram manually. Then the detection of microcalcifications has been achieved by wavelet transform. Classification of microcalcifications into benign and malignant classes has been implemented using wavelet features and two types of classifiers, support vector machine and artificial neural network classifier. A set of 52 images is used from MIAS database where in 26 images are normal, 26 images are microcalcified. Out of 26 abnormal images 15 are having benign microcalcifications and 11 are having malignant microcalcifications. $79.58 \%$ and $99.04 \%$ accuracy values have been obtained for SVM and ANN methods respectively to detect MCs. The accuracy of classification of benign and malignant microcalcification using SVM was $69 \%$ and that using ANN is $96 \%$.

Association rule-based classification method with GLCM features were used in another approach for detection of MC clusters (Herwanto et al., 2013). Here; contrast, correlation, energy, homogeneity and mean, median, variance, skewness, kurtosis features were extracted as GLCM texture features and statistical features respectively. Then, the limit values of these features were defined by association rules for classification.

(Jelvehfard et al, 2013) used two-dimensional wavelet transform to extract features of suspicious MC regions in different sizes and then the classification process was implemented by the support vector machine (SVM) method, For detection of MC clusters, mathematical morphology and artificial neural network (ANN) methods were implemented by (Halkiotis et al., 2007). In the study (Jasmine et al., 2009), features were defined by wavelet transform for suspicious MC regions. However, the number of features was too much, and then energy values of wavelet coefficients were computed to reduce that number. For classification process ANN was implemented. (Pal et al., 2008) extracted 24 features which were mean, variance, average power, kurtosis, skewness, contrast, etc. and used ANN for the classification process. Consequently, due to the successful description of MC clusters, textural and statistical features are usually preferred for feature extraction. For classification of suspicious MC regions, ANN and SVM methods are widely used.

(Vivona et al., 2014) presented a clustering method for microcalcifications based on fuzzy logic which was called Fuzzy C-Mean with features (FCM-WF). They used shape and grey level based features. The FCM-WF method has been tested on 20 images belonging to MIAS database and obtained $82 \%$ sensitivity with $4 \% \mathrm{FP} / \mathrm{Im}$. Another automatic microcalcification detection method based on type II fuzzy index was proposed by (Mohanalin et al., 2010). The thresholding was performed using the Tsallis entropy characterized by a parameter $q$. They proposed type II fuzzy index to find the optimal value of q. They obtained $93.75 \%$ sensitivity with $0.52 \mathrm{FppI}$ on 23 abnormal (MC) and 18 normal mammograms 
from MIAS database. (Diaz-Huerta et al., 2014) applied a morphological algorithm and extended maxima thresholding as a preprocessing step for detection of MCs. Then spatial, spectral and textural features were extracted and classified by SVM. The obtained performance results were $86.6 \%$ sensitivity, 84.36 specificity and $1.77 \mathrm{FppI}$ on $22 \mathrm{MC}$ abnormal mammograms from MIAS database. Furthermore, they tested their system on 45 normal mammograms and obtained 0.71 FppI rate.

(Dheeba et al., 2014) presented detection of breast cancer abnormalities such as masses and microcalcifications. They used laws texture energy measure and particle swarm optimized wavelet neural network (PSOWNN) methods for extracting features and classification respectively. The AUC value of the proposed algorithm is 0.969 with a sensitivity $94.167 \%$ of and specificity of $92.105 \%$ for 216 malign abnormal mammograms. 24 mammograms of 216 include malign microcalcifications while the remaining includes malign masses. In another study, to detect MC clusters cascade-based (CasCADe) approach was used (Bria et al., 2014). The proposed CasCADe system consists of a preprocessing stage, an initial detection stage and a classification stage in which the number of false positive detected clusters is reduced. The detection performance of CasCADe was compared with the one of the commercial CADe systems, the Hologic R2CAD ImageChecker. They have mentioned that the results are a bit better than R2CAD. (Rizzi et al., 2012) presented the various methods adopted for microcalcification cluster detection and compares their performance. They have defined that comparisons of CAD method performance are very difficult and even impossible due to the use of different databases for testing. In addition to these, a CAD system with a low specificity value leads to many false positives with subsequent psychological stress experienced by patients in clinical application. In contrast, a low sensitivity leads to false negatives, which produce false reassurance associated with cancer detection at a more advanced stage when more intensive treatments are required. Therefore, they have proposed that studies should take into account the integration of various classifiers for FP and FN reduction.

(Zyout et al., 2015) mentioned that the high number of false positives and the resulting number of avoidable breast biopsies are the major problems faced by current mammography computer aided detection (CAD) systems. Furthermore, they have emphasized that false positive reduction is not only a requirement for mass but also for calcification CAD systems which are currently deployed for clinical use. Therefore, they focused on reducing the number of false positives in the detection of all lesions and masses. With this aim, textural patterns of breast tissue have been analyzed using several multi-scale textural descriptors based on wavelet and gray level co-occurrence matrix. Then a model selection procedure based on particle swarm optimization (PSO) for selecting the most discriminative textural features and for strengthening the generalization capacity of the supervised learning stage based on a support vector machine (SVM) classifier have been implemented. As a result, they have mentioned that the proposed PSO based model selection is a versatile tool for solving false positive reduction problem adequately.

(Sabu et al., 2012) have discussed various methods of texture analysis for mass detection and micro calcification in mammography. They observed various texture analysis approaches such as GLCM, GLRLM etc. for the detection of masses and micro calcification in mammography and identified the texture features obtained from each texture descriptor. As a result, it has been proposed that texture analysis can help to identify the disease pattern of breast cancer in mammography.

(Thangavel et al., 2009) proposed a rule based system for classification of microcalcifications. Shape features were extracted and with these feature values association rules have been constructed. For rule construction, a novel multi-dimensional genetic association rule miner (MGARM) algorithm was used. The proposed approach reached the classification accuracy of $85.26 \%$ on MIAS database.

(Karahaliou et al., 2007) analysed a case sample of 100 biopsy-proved MC clusters (46 benign, 54 malignant) from 85 dense mammographic images, included in the Digital Database for Screening Mammography. MCs were segmented from original ROI images by local thresholding after wavelet based enhancement. Four categories of textural features (first order statistics, co-occurrence matrices features, run length matrices features and Laws' texture energy measures) were extracted from tissue area surrounding MCs. The ability of each feature category in discriminating malignant from benign 
tissue was investigated using a k-nearest neighbour (KNN) classifier. The proposed approach had a sensitivity of $94.4 \%$ and specificity of $80.0 \%$.

(Mohamed et al., 2014) have implemented Otsu's thresholding based segmentation after enhancement step for the identification of microcalcifications and mass lesions. After that, they classified these ROIs between normal and microcalcifications' patterns and then classified between benign and malignant microcalcifications. In classification stage; three methods were used, the voting $\mathrm{K}$-nearest neighbor classifier $(\mathrm{KNN})$ with prediction accuracy of $73 \%$, SVM classifier with prediction accuracy of $83 \%$, and ANN classifier with prediction accuracy of $77 \%$. For the study, 97 normal and 84 abnormal (23 of them were MCs) mammograms were used from MIAS database.

(Strange et al., 2014) presented classification of microcalcification clusters by representing discrete mereotopological relations between the individual microcalcifications over a range of scales in the form of a mereotopological barcode. For this aim, manually selected ROI images were used and microcalcification clusters were segmented by binary image conversion. The mereotopological barcode was used to represent the persistent mereotopology of a microcalcification cluster. Classification these mereotopological barcodes have been performed by employing a nearest neighbour based strategy between a test barcode and the set of all training barcodes using the above metric as the distance metric. Classification accuracies of $95 \%$ and $80 \%$ were achieved on the MIAS and DDSM datasets, respectively. For the MIAS dataset, 9 malignant and 11 benign clusters were tested.

(Suba et al., 2015) used dual tree m-band wavelet transform (DTMBWT) to represent the digital mammogram in a multiresolution manner for feature extraction. After selecting ROI manually, DTMBWT transform has been applied and the extracted sub band energies from DTMBWT decomposed mammograms were used as distinguishable features for the classification of MCs into either malignant or benign by SVM classifier. The results show that the proposed DTMBWT based classification system achieved $91.83 \%$ accuracy on MIAS database images.

In the proposed system, firstly breast region segmentation and enhancement processes have been implemented as a preprocessing step. After that suspicious MC regions have been segmented by using Otsu's N thresholding method. For detection of MC clusters, some GLCM textural and statistical features have been extracted and classified with a multilayer perceptron (MLP) neural network. Then, to reduce the number of false positive regions, grey level run length matrix (GLRLM) features and cascade correlation neural network (CCNN) have been used.

In our previous study (Kurt et al., 2015), which is a pre study of this paper, enhancement and segmentation processes were implemented. Suspicious MC pixels have been segmented using Otsu's N thresholding and connected component labeling methods. In this paper, we have defined MC ROIs using segmented suspicious pixels from the previous study, then detected MC clusters and finally classified detected MC clusters into benign or malign automatically. Thus, an automatic CAD system for MCs has been developed for breast cancer.

As shown in Figure 1, an automated whole CAD system for MC clusters has been proposed. Enhancement and segmentation processes were implemented in our previous study (Kurt et al., 2015) as mentioned before. Identification of MC ROIs is given in the following section. 


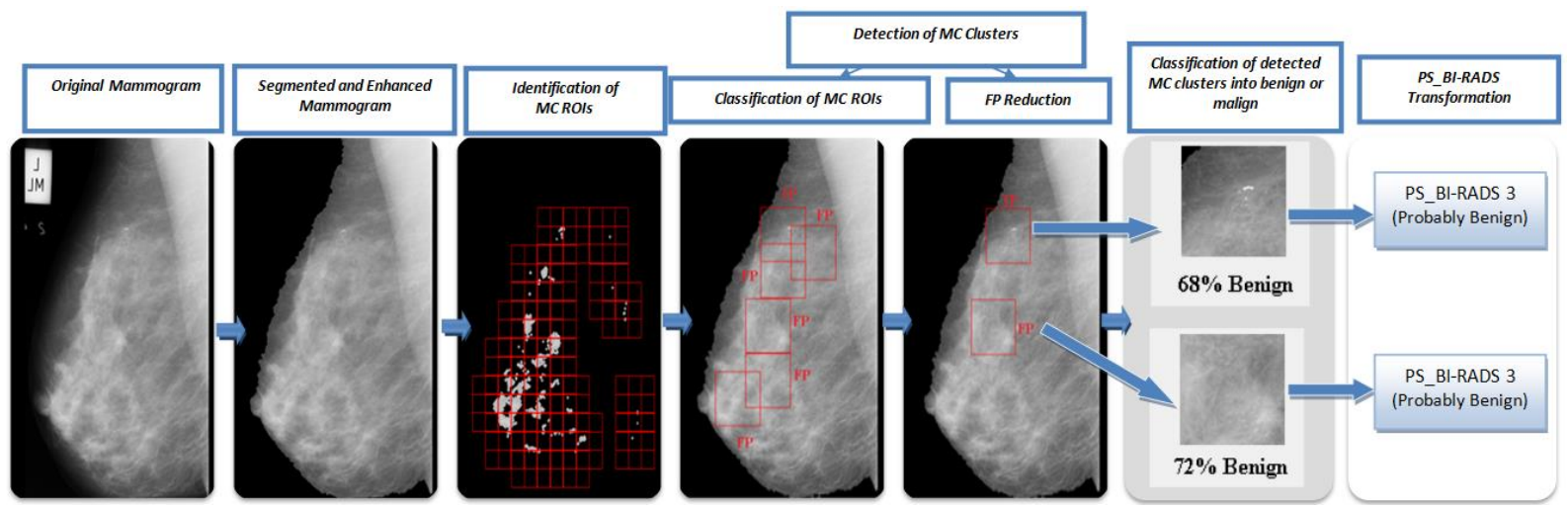

Figure 1. The scheme of the proposed system (Mdb219, biopsy result is benign)

\section{IDENTIFICATION OF MC ROIS}

In this section, we have used the output results of our previous study (Kurt et al., 2015). The outputs of our previous study are given step by step in Figure 2 .

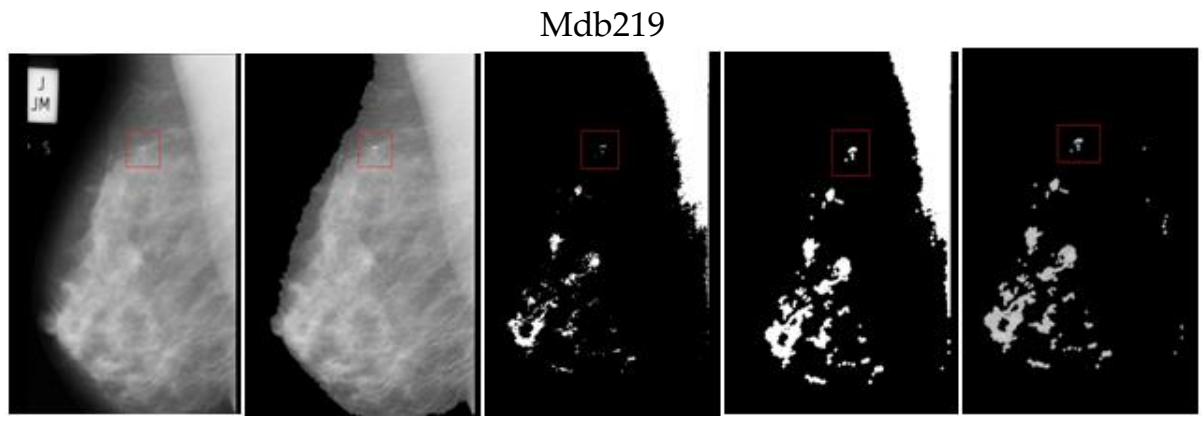

$\mathrm{Mdb} 253$

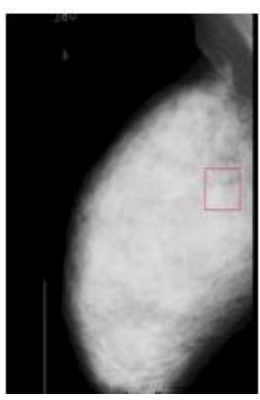

(a)

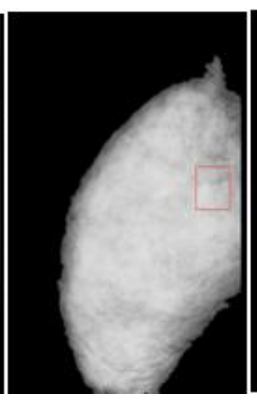

(b)

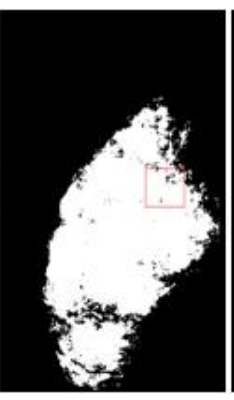

(c)

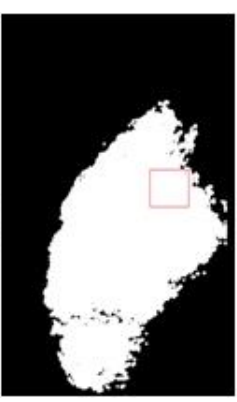

(d)

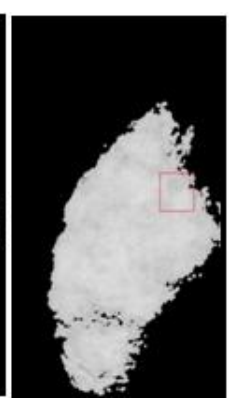

(e)

Figure 2. (a) Original mammogram (b) segmented and enhanced mammogram (c) Otsu's $N=3$ thresholding (d) dilation (e) suspicious MC pixels

As shown in Figure 2, the pectoral muscle regions were extracted despite of their different sizes. However, for some mammograms segmentation process of suspicious MC pixels is not very efficient such as Mdb253 due to their dense glandular breast tissue types. Despite this, for dense glandular mammograms, MC clusters can also be detected successfully by the proposed classification methods which are given in the next section.

After segmentation of suspicious MC pixels, we scanned these pixels by a $50 x 50$ sized window with half of the window size intervals. Thus, we identified suspicious regions of MC clusters which were called MC ROIs as given in Figure 3. 


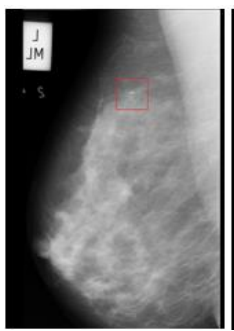

(a)

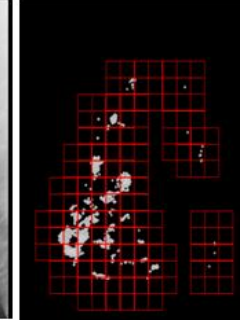

(b)

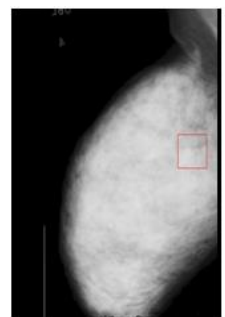

(a)

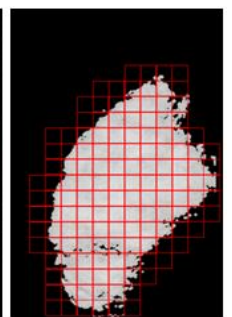

(b)

Figure 3. (a) Original mammogram (b) identified MC ROIs

As shown in Figure 3, the segmentation result for $M d b 253$ is not so efficient because of the quite dense breast tissue. Therefore, the number of ROIs for Mdb253 is greater than the number of ROIs for Mdb219. Thus, we identified MC ROIs, and then analyzed each ROI to detect MC clusters.

\section{DETECTION OF MC CLUSTERS}

In this section, we focused on MC ROIs for detection of MC clusters. The detection process was examined in two parts as classification of MC ROIs and FP reduction.

\section{Classification of MC ROIs}

In this study, to classify MC ROIs, we used some texture and statistical features with MLP neural network. Cluster prominence, energy, contrast, information measure of correlation and inverse difference moment normalized features were extracted as GLCM texture features. Mean, variance, skewness and kurtosis features were extracted as statistical features. As a result, we have obtained 9 features for each ROI.

The GLCM represents the second order statistical texture features and first presented by (Haralick et al., 1973). It can be computed in four directions $\left(0^{\circ}, 45^{\circ}, 90^{\circ}\right.$, and $\left.145^{\circ}\right)$ and four distances $(1,2,3$, and 4$)$. GLCM is a $M x N$ size matrix where $M$ and $N$ are equal to the number of gray levels, $G$, in the image (Albregsten, 2008). $P(i, j \mid d, \theta)$ represents the matrix element which is simply the sum of the number of times that the pixel with value $i$ occurred in the specified spatial relationship to a pixel with value $j$ in the input image. Spatial relationship is defined with a displacement distance $d$ and an angle $(\Theta)$.

As an example of $5 \times 5$ image with 4 gray levels and its corresponding gray level co-occurrence matrix $P(i, j \mid \Delta d=1, \Delta \Theta=0)$ is given in Figure 4 .
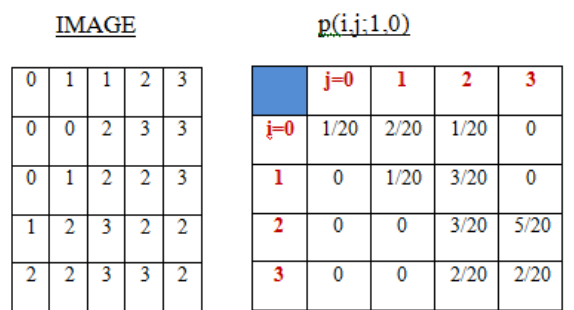

Figure 4. GLCM matrix example for a 5x5 image

In GLCM; each combination of $(d, \theta)$ needs a lot of temporary data and memory (Albregsten, 2008). In this study, we have taken $d=1$ and $\theta=0^{\circ}$ to compute the co-occurrence matrix using consecutive pixels in zero direction to define the ROI texture and to reduce the computation complexity. To describe GLCM features some notations are used as in the following:

$$
P_{x}(i)=\sum_{j=0}^{G-1} P(i, j) \quad P_{y}(j)=\sum_{i=0}^{G-1} P(i, j)
$$




$$
\begin{aligned}
& \mu=\sum_{i, j=0}^{G-1} i P(i, j) \\
& \mu_{x}=\sum_{i=0}^{G-1} i p_{x}(i) \quad \mu_{y}=\sum_{i=0}^{G-1} j p_{y}(j) \\
& \sigma_{x}^{2}=\sum_{i=0}^{G-1}\left(P_{x}(i)-\mu_{x}(i)\right)^{2} \\
& \sigma_{y}^{2}=\sum_{i=0}^{G-1}\left(P_{y}(j)-\mu_{y}(j)\right)^{2} \\
& P_{x+y}(k)=\sum_{i=0}^{G-1} \sum_{j=0}^{G-1} P(i, j) \quad \text { for } k=0,1, \ldots, 2(G-1) \\
& H X Y=-\sum_{i, j=0}^{G-1} P(i, j) \log _{2} P(i, j) \\
& H X Y 1=-\sum_{i, j=0}^{G-1} P(i, j) \log _{2}\left(P_{x}(i) P_{y}(i)\right)
\end{aligned}
$$

In mathematics, moment is a quantitative measure related with the shape of a series of dots. According to this; first, second, third and fourth moments give the mean, variance, skewness and kurtosis respectively.

For classification, we have developed a MLP neural network model with STATISTICA12 CStatSoft which was trained using BFGS (Broyden, Fletcher, Goldfarb and Shanno) (Dennis et al., 1996) training algorithm. BFGS algorithm is a fast, efficient learning algorithm based on the second order Newton optimization methods and is an iterative method for solving unconstrained nonlinear optimization problems. BFGS methods do not need to converge unless the function has a quadratic Taylor expansion near an optimum and use both the first and second derivatives of the function. However, BFGS has proven to have good performance even for non-smooth optimizations (Nocedal et al., 2006). The network was trained by Statistica12@StatSoft and validated using 10 fold cross-validation.

In this study for classification of Mc ROIs, the numbers of neurons of the developed ANN are 9, 21 and 2 for input, hidden and output layers respectively. Furthermore, the results of the training performance for the developed ANN are given in Table 1.

Table 1. Training performance of the developed ANN for classification of MC ROIs

\begin{tabular}{|c|ccc|}
\hline \multicolumn{3}{|c|}{ ANN } \\
\hline Total & MC ROIs & Normal ROIs & All \\
Correct & 20 & 213 & 233 \\
Incorrect & 20 & 213 & 233 \\
Training & 0 & 0 & 0 \\
Performance & $\mathbf{\% 1 0 0}$ & $\mathbf{\% 1 0 0}$ & $\mathbf{\% 1 0 0}$ \\
\hline
\end{tabular}

As seen in Table 1, we can say that the training process has been implemented successfully for classification of MC ROIs. Thus, we obtained regions of MC clusters. But some overlapped windows have been seen and to overcome this problem we have developed a box merge algorithm. According to 
this algorithm, if the distance between two windows is equal or smaller than the half size of window then we decide that they are overlapped windows. From these overlapped windows, the window which has the maximum number of suspicious pixels is selected. By the proposed box merging algorithm, the overlapped detections are reduced. Furthermore, we enlarged the detected window, 15 pixels in four directions to enclose scattered MC clusters and we have obtained the new window size as 80x80. Thus, detection of MC clusters process is completed. The detection results of the proposed algorithm are given in Figure 5.

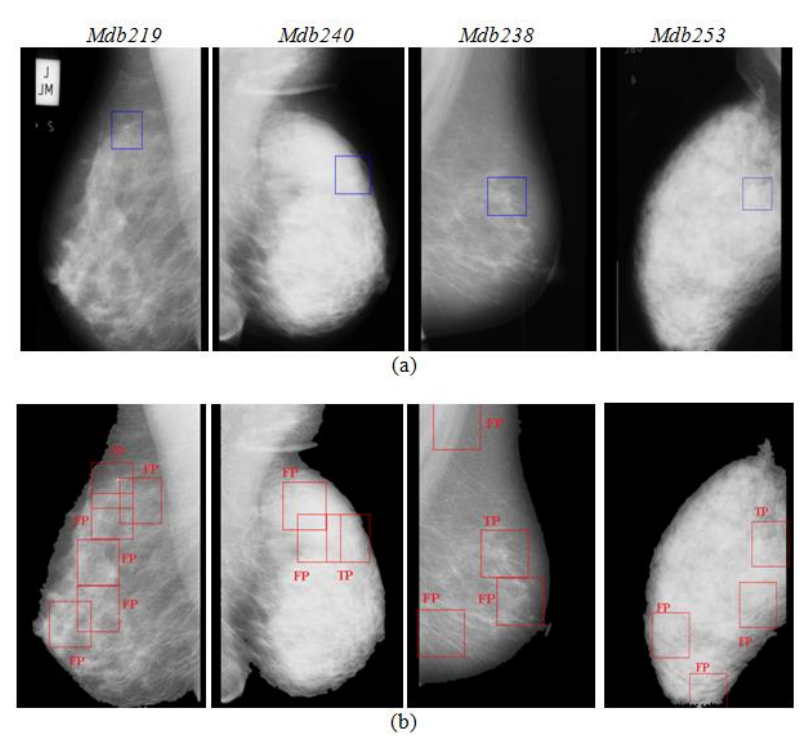

Figure 5. (a) Original mammograms (b) The detection results for the proposed algorithm

As seen in Figure 5, the number of FP regions is a bit much because of the difficulty of the problem such as structures of MC clusters and different tissue types. Therefore, we proposed a FP reduction algorithm to reduce the number of FP regions.

\section{False Positive Reduction}

In this study, FP regions represent the regions that do not contain MC clusters but they are detected as regions of MC clusters. Thus, high FP rate is a problem for computer aided detection and diagnosis systems because of decreasing the accuracy. Therefore, we have implemented feature extraction and classification steps for FP reduction process. For this purpose, we have used statistical and GLRLM features with cascade correlation neural network $(\mathrm{CCNN})$ method.

\section{Grey level run length matrix (GLRLM)}

GLRLM is a matrix which extracts texture characteristics for texture analysis. Texture can be understood as gray level pixel pattern in a specific direction from the reference pixel. The array length is the number of neighboring pixels with the same gray level values in a specific direction (Mohanty et al., 2011).

Texture properties can be determined by using the neighbor pixels which have the same gray level. Neighboring pixels lengthily with the same grey level, represents thick line rough texture. On the other hand, fewer neighboring pixels with the same grey level, represents finer texture and rapid changes (Ergen et al., 2011). If GLRLM represented by $P, P(i, j)$ is the value of $i$ the value of certain specified positional relationship with the $j$ value indicates how many times combined. This can be explained as follows, $P(i, j)$ indicates the number of times that the gray level $i$ occurs in length $j$. 
This definition angularly can be carried out for different aspects such as $0^{\circ}, 45^{\circ}, 90^{\circ}, 135^{\circ}$ and the most common use including descriptions made in the horizontal direction. GLRL method is based on the calculation of the number of gray levels of different lengths.

As an example of $6 \times 6$ image with 3 gray levels and its corresponding GLRL matrix $P(i, j \mid \theta=0)$ is given in Figure 6.

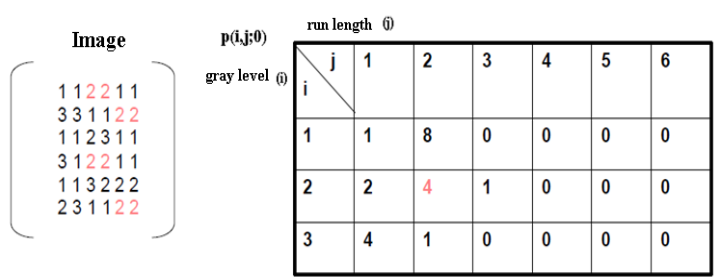

Figure 6. GLRL matrix example for a $6 \times 6$ image

A gray level length is a linear neighboring pixels' array having the same gray level value. Length is the number of pixels in the gray level array (Ergen et al., 2011).

For FP reduction we used some GLRLM features (Radhakrishnan et al., 2012; Xu et al., 2004) such as short run emphasis (SRE), long run emphasis (LRE), run length non-uniformity (RLNU) and run percentage (RPC). Furthermore, we extracted skewness, variance as statistical features and homogeneity as a GLCM feature. As a result, we have obtained 7 features for FP reduction process. After that, we used CCNN method for classification.

\section{Cascade correlation neural network (CCNN)}

CCNN was first developed by Fahlman and Libiere (Fahlman et al., 1990) in 1990 and is characterized as a constructive learning rule. CC is a productive and supervised feedforward learning architecture. CC starts with a minimal network structure to consist of input and output layer, then train and automatically creates multi-layered network structure by adding individual elements of the hidden layer (Sharma et al.,, 2014). CCNN is first trained with appropriate learning data. The educational training procedure is terminated when a significant reduction occurs in the approximation error or a certain iteration number is reached. The obtained weights are frozen (Gao et al., 2009). The architecture of the CCNN is given in Appendices A1.

All inputs and outputs are connected to each other with an adjustable weight value $w_{i j}$. Also, there is a deviation input which is taken as a constant value +1 (Kovalishyn et al., 1998). Training algorithm starts without hidden neurons and hidden neurons are individually added to the network. Each added hidden neuron receives a connection from the original input and existing hidden neurons of the network. Input weights of each hidden neuron are frozen after being added to the network. So, each new neuron adds a new neuron layer to the network. Output connections are retrained after a new hidden neuron is added.

It can learn 10 times faster than the standard feedback algorithms (Sharma et al., 2014). Network, can decide its size and topology. It is an incremental learning and is useful for adding new information to already trained network.

\section{CCNN Training Algorithm:}

Step 1. Starts the CCN network that consists of only input and output layers.

Step 2. All input neurons are connected to the output neurons with adjustable weights. Each input neuron value is multiplied by its own weight and the sum of input weight value of all input neurons is calculated. Then the weighted input sum is sent to the output neurons with the deviation value $(+1)$.

Step 3. Candidate unit is formed which takes connections from each input unit and hidden units. Initially, there are no connection and weights between candidate and output units. 
Step 4. Connections to the each candidate unit are trained with the selected standard learning algorithm to to maximize the network error (residual error) and the correlation between the activation of candidate units. The purpose of this setting is to maximize the $\mathrm{S}$ (the sum over all output units o) (Chandra et al., 2007). $S$ can be defined as follows:

$$
S=\sum_{o}\left|\sum_{p}\left(V_{p}-\bar{V}\right)\left(E_{p, o}-\overline{E_{o}}\right)\right|
$$

Where $o$, output neuron; $p$, training sample; $V p$, candidate output for training sample $p ; E_{p, o}$, error of the output neuron $\mathrm{o}$. In addition to these, $\overline{\mathrm{V}}$ and $\overline{\mathrm{E}_{\mathrm{o}}}$ show the averages of the all training samples of $V_{p}$ and $E_{p, o}$ respectively. Partial derivative of $S$ can be calculated using the following formula to maximize $S$, according to the coming weights from each candidate neuron.

$$
\frac{\partial S}{\partial w_{i}}=\sum \sigma_{o}\left(E_{p, o}-\overline{E_{o}}\right) f_{p}^{\prime} I_{i, p}
$$

Here $\sigma_{o}$, shows the correlation between candidate neuron $o$, and output neuron. $\mathrm{f}_{\mathrm{p}}^{\prime}$, represents the derivative for $\mathrm{p}$ sample according to the sum of input values of activation function of candidate unit and $\mathrm{I}_{\mathrm{i}, \mathrm{p}}$ is the input where candidate unit takes from $\mathrm{i}$ unit for sample $\mathrm{p}$. After calculating $\partial \mathrm{S} / \partial \mathrm{w}_{\mathrm{i}}$ for each incoming connection, gradient output is applied. Only one layer of weights is trained. If there is no improvement in $S$ or a predefined number of iteration is reached, the process is stopped.

Step 5. Candidate unit joins to the network and the input weights are frozen.

Step 6 . To change the candidate unit as the hidden neuron, connection between candidate unit and all output units is formed.

Step 7. If the trained example is not learned by acceptable error value, then go to Step 2. Otherwise, the training process for that sample is completed.

The network was trained by DTREG software and validated using 10 fold cross-validation. The training performance results of the developed CCNN models are given in Appendices A1 and A2.

As seen in Appendix, CCNN_1 gives the best performance result and it uses the Gauss kernel function. Therefore, we used the CCNN_1 model for the classification process to reduce the FP regions. The results of some mammograms are given in Figure 7.

As seen in Figure 7, FP regions have been reduced successfully which provides quite satisfactory results for detection of MC clusters. Furthermore, despite the difficulty of dense breast types, the proposed detection algorithm gives successful results. 

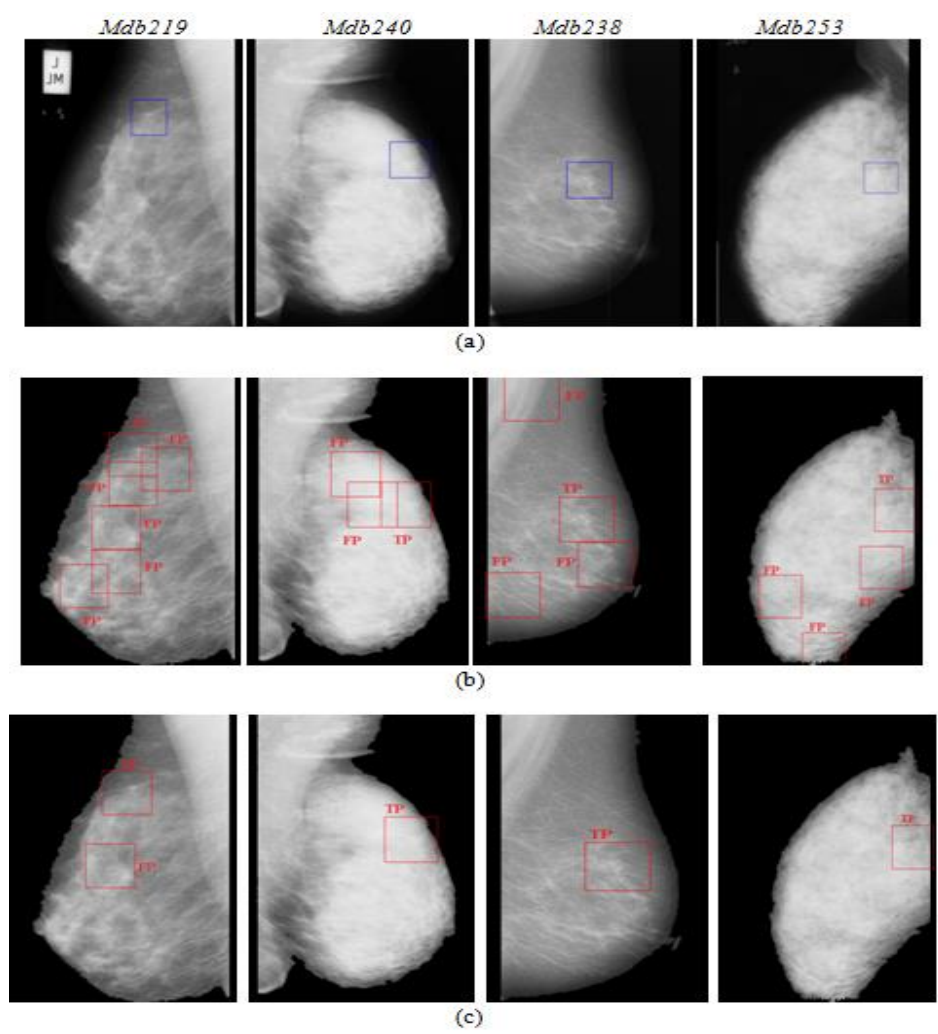

Figure 7. (a) Original mammograms (b) The detection results (c) FP reduction result

\section{CLASSIFICATION OF DETECTED MC CLUSTERS INTO BENIGN OR MALIGN}

Calcifications are defined as calcium deposits in breast tissue. Benign calcifications are usually larger and coarser with round and smooth contours. While malignant calcifications tend to be numerous, clustered, small, varying in size and shape, angular, irregularly shaped and branching in orientation.

In this section, we have focused on detected MC clusters in the previous part and tried to classify them into benign or malign. For this aim, feature extraction and classification processes have been implemented. To define MC clusters skewness, contrast, mean, homogeneity, LRE, LGRE, HGRE, SRHGE and RPC features were extracted. The formulas and explanations for these features are given in Appendices A2 and A3.

For classification, discriminant analysis (DA) and SVM methods have been implemented. The training processes for the proposed methods have been performed by DTREG software and validated using 10 fold cross-validation.

There are 13 benign and 15 malign MC clusters in MIAS database. The training performance results for the proposed methods are given in Table 2.

As seen in Table 2, the training performance results of DA and SVM_RBF kernel models are same and better than SVM_Sigmoid kernel model. Therefore, these models were selected and tested on the test samples.

For MC cluster, deciding as benign or malign absolutely is almost impossible without biopsy. Therefore, the classification results of benign or malign have been given as probabilistic values in this study. Thus, unlike similar studies in literature which have given definite results as benign or malign, the proposed system has given more reliable and accurate results by using probabilistic approach. The classification results of some test examples for the DA and SVM_RBF kernel models are given in Table 3. 
Table 2. Training performances of the developed models for benign/malign classification

\begin{tabular}{|c|c|c|c|c|c|c|c|c|c|}
\hline & \multicolumn{3}{|c|}{ DA } & \multicolumn{3}{|c|}{ SVM_RBF Kernel } & \multicolumn{3}{|c|}{ SVM_Sigmoid Kernel } \\
\hline & Benign & Malign & All & Benign & Malign & All & Benign & Malign & All \\
\hline Total & 8 & 9 & 17 & 8 & 9 & 17 & 8 & 9 & 17 \\
\hline Correct & 7 & 8 & 15 & 7 & 8 & 15 & 6 & 8 & 14 \\
\hline Incorrect & 1 & 1 & 2 & 1 & 1 & 2 & 2 & 1 & 3 \\
\hline $\begin{array}{c}\text { Training } \\
\text { Performance }\end{array}$ & $\% 87.5$ & $\% 88.88$ & $\% 88.23$ & $\% 87.5$ & $\% 88.88$ & $\% 88.23$ & $\% 75$ & $\% 88.88$ & $\% 82.35$ \\
\hline
\end{tabular}

Table 3. Classification results of some test examples for the DA and SVM_RBF kernel models

\begin{tabular}{|c|ccccc|}
\hline $\begin{array}{c}\text { MC Cluster } \\
\text { Region }\end{array}$ & \multicolumn{2}{|c}{ DA Model } & \multicolumn{2}{c|}{ SVM_RBF Kernel Model } & Biopsy Result \\
& Result & Probability & Result & Probability & (from MIAS Database) \\
\hline 1 & Malign & $\mathbf{7 0} \%$ & Benign & $\mathbf{6 8 \%}$ & Malign \\
2 & Benign & $64 \%$ & Benign & $75 \%$ & Benign \\
3 & Benign & $81 \%$ & Benign & $70 \%$ & Benign \\
4 & Benign & $\mathbf{5 7 \%}$ & Malign & $\mathbf{5 6 \%}$ & Benign \\
5 & Malign & $88 \%$ & Malign & $84 \%$ & Malign \\
6 & Malign & $69 \%$ & Malign & $94 \%$ & Malign \\
\hline
\end{tabular}

As shown in Table 3, if the results of proposed models are same, the results are correct but if not, the DA model result is correct based on the biopsy results. According to these results, a decision algorithm has been developed by using voting model as given in Figure 8 .

As given in Figure 8, a weighted voting approach has been used for decision. If the outputs of the developed models are the same, the system output is equal to them and the probability of the output is (2 ${ }^{*}$ DA probability + SVM probability) / 3. However, if the outputs are different, the system output is taken as the DA_Result and the probability of the output is equal to the DA probability.

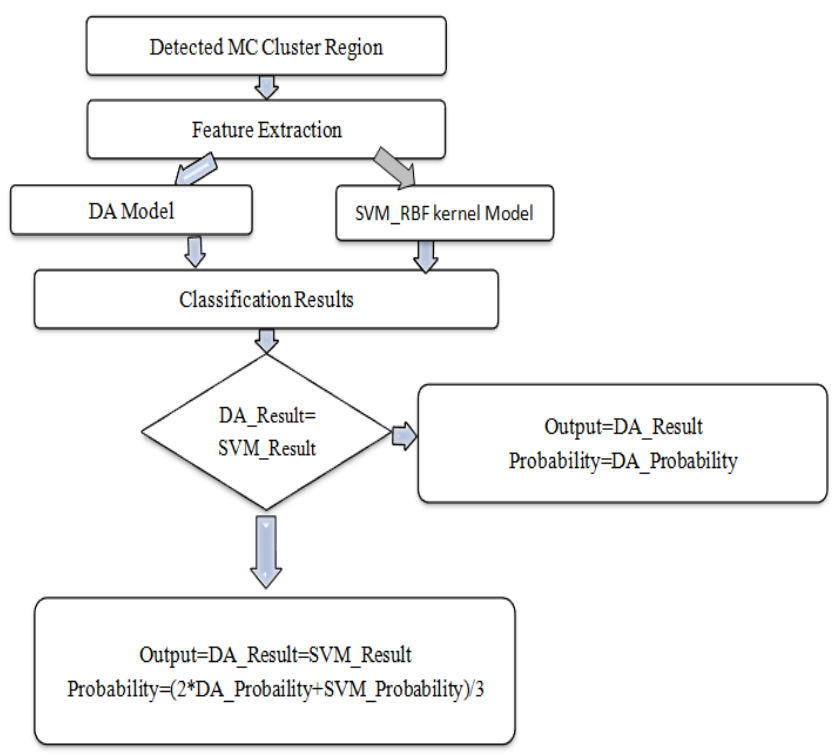

Figure 8. The developed algorithm for classification of MC Cluster into benign or malign 


\section{TRANSFORMATION BASED ON BI-RADS ASSESSMENT CATEGORIES}

The American College of Radiology (ACR) came up with a standard way to describe mammogram findings and results (The American College of Radiology, 2013). In this system, the results are sorted into categories numbered 0 through 6. This system is called the Breast Imaging Reporting and Data System (BI-RADS). The BI-RADS assessment is given in Appendices A4.

The probabilistic results of the proposed system have been transformed to categories based on BIRADS assessment categories which are called proposed system BI-RADS categories (PS_BI-RADS). For this aim, the distributions of probability values of benign and malign MCs have been used which are given with the following graphics in Appendices A5.

We have computed mean probabilities for both distributions and used them as thresholds between categories. The mean values of the distrubitions of benign and malign probabilities are $72 \%$ and $75 \%$ respectively. The transformation table for the proposed study based on the BI-RADS assessment categories is shown in Table 4.

Table 4. The PS_BI-RADS tranformation table based on BI-RADS assessment categories

\begin{tabular}{|l|cll|}
\hline $\begin{array}{l}\text { PS_BI-RADS Assessment } \\
\text { Category }\end{array}$ & $\begin{array}{c}\text { PS_BI-RADS } \\
\text { Numeric Code }\end{array}$ & \multicolumn{2}{c|}{ The Proposed System Result } \\
\hline Benign & $\mathbf{2}$ & $72 \%<$ & Benign \\
Probably Benign & $\mathbf{3}$ & $<=72 \%$ & Benign \\
$\begin{array}{l}\text { Suspicious } \\
\text { Highly Suggestive of }\end{array}$ & $\mathbf{4}$ & $<=75 \%$ & Malign \\
$\begin{array}{l}\text { Malignancy } \\
\text { Known Biopsy-Proven }\end{array}$ & $\mathbf{5}$ & $75 \%<$ and $<=95 \%$ & Malign \\
Malignancy & $\mathbf{6}$ & $95 \%<$ & Malign \\
\hline
\end{tabular}

As seen in Table 4, the transform categories started from numeric code 2 due to defining the benign or malign situation of the abnormality. The mean probability values have been used as thresholds for benign and malign categories. Furthermore, the probability for category 6 has been taken as greater than 95\% (the top $\% 5$ part which is between $95 \%$ and $100 \%$ ) based on the significance level probability value $5 \%$ in statistics. Thus, we have presented a novel approach by the proposed assessment category which has never been used in literature before.

The breast cancer diagnosis results for the detected MC clusters of some mammograms are given in Figure 9.
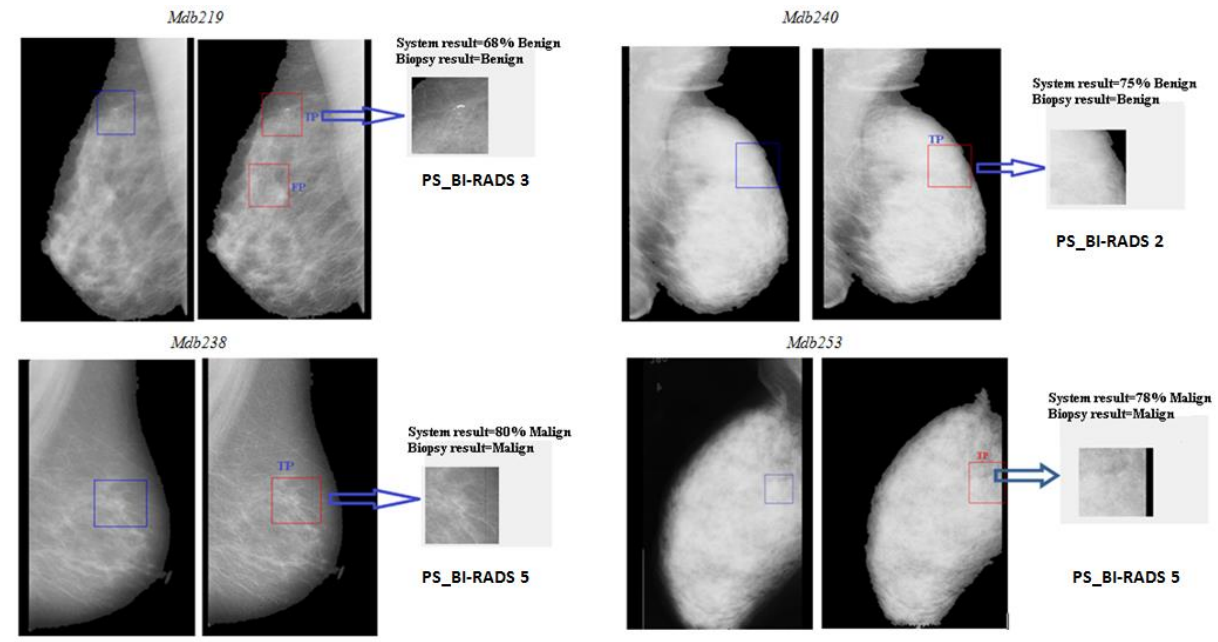

Figure 9. The proposed algorithm results of some mammograms for breast cancer diagnosis (original mammogram, the proposed system detection result and the proposed system breast cancer diagnosis result) 


\section{EXPERIMENTAL RESULTS}

For the study, an open access Mammographic Image Analysis Society (MIAS) database (University of Essec, 2014) was used. It contains 321 digitized mammogram images of which 55, 23, 19, 15 include mass, microcalcification, architectural distortion, asymmetry abnormalities respectively and 209 are normal. In this study, we have focused on $23 \mathrm{MC}$ and 209 normal mammograms to detect MC clusters. The images in the database are digitized at 50-micron pixel edge, which are then reduced 200-micron pixel edge and every image has 1024x1024 pixels. Furthermore, the details regarding the characters of background tissue, class, severity, coordinates of center of abnormality and approximate radius of the circle enclosing it, are given.

The database includes 209 normal images, 23 images of CIRC (Circumscribed masses), 19 images of SPIC (Speculated masses), 19 original images of MISC (Ill-defined masses), 23 images of CALC (Calcification). Thus, we have used 23 CALC and 209 normal images in the study. As a result of suspicious regions identification, we have obtained $28 \mathrm{MC}$ and 15715 normal ROI regions.

\section{Performance Evaluation for Automatic Detection of MC Clusters}

For statistical analysis of the proposed detection system, we have computed TP, FP, FN and TN values and compared the results in Appendices A6.

In this study, the success of the detection system has increased by two step classification. In the first step, we classified ROIs using ANN and reduced the searched area as detected MCs by ANN. Then, the detection results of ANN were classified by CCNN in the second step and thus, the final MC regions have been obtained. As a result, we can say that the system was strengthened by FP reduction. The FP rates are 0.07 and 0.017 without FP reduction and with FP reduction respectively.

The area under the ROC curve (AUC) is the most commonly used metric in CAD studies and the AUC index for useful classifiers is constrained between 0.5 (representing chance behaviour) and 1.0 (representing perfect classification performance) (Mazurowskia et al., 2008). ROC curve and AUC index of the proposed system have been obtained using MedCalc software program (Medcalc statistical software, 2014) which are given in Figure 10.

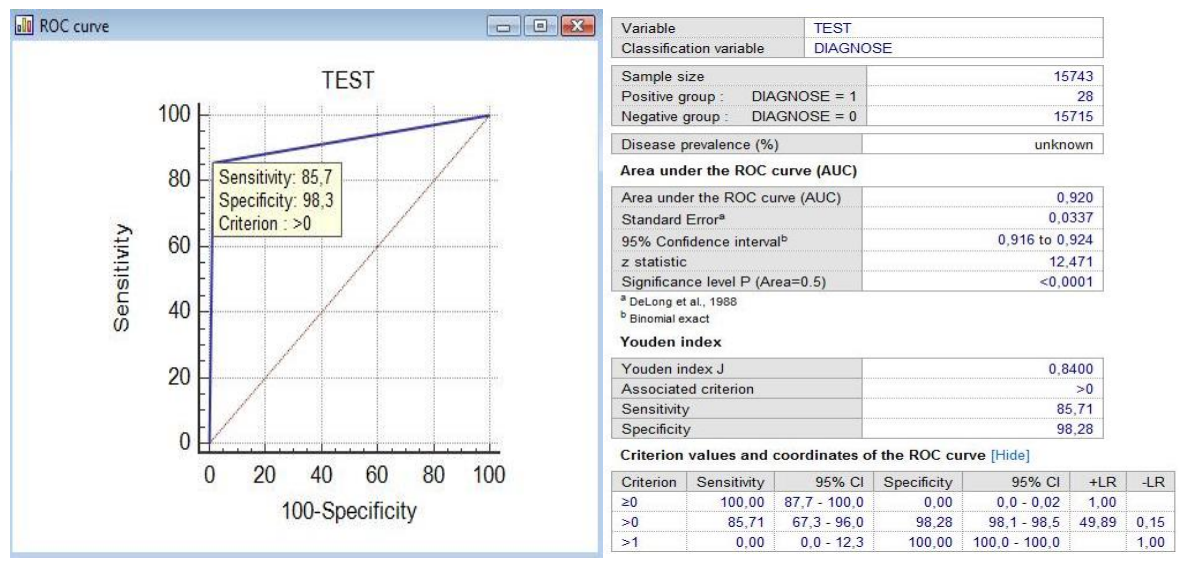

Figure 10. ROC curve and AUC index for the proposed MCs detection system

As shown in Figure 10; sensitivity, specificity and AUC index values were obtained as $85.7 \%, 98.3 \%$ and 0.92 respectively. Furthermore, the graphics of $T P R$ (true positive rate) with $F P R$ (false positive rate) and TNR (true negative rate) with FNR (false negative rate) have been plotted using Rstudio as seen in Appendices A7.

The computed TPR, FPR, TNR and FNR values are 0.857, 0.017, 0.983 and 0.143 respectively. In addition to these, the obtained $L R+$ and $L R$ - values are 50.412, and 0.145 . The positive and negative likelihood ratios ( $L R+$ and $L R-$, respectively) quantify the change in the certainty of the "diagnosis" 
conferred by test results. If a given test has very good ability to predict the "true disease status," its positive likelihood ratio will be high (i.e., will greatly increase the odds of a positive diagnosis) and its negative likelihood ratio will be low (i.e., will diminish substantially the likelihood of the positive diagnosis). Typically, a positive likelihood ratio of 10 or more and a negative likelihood ratio of 0.1 or less are considered to represent informative tests.

Consequently, we can say that the results are quite satisfactory and indicate the success of the system. The program results of some mammograms for the developed detection system can be observed in Figure 11.

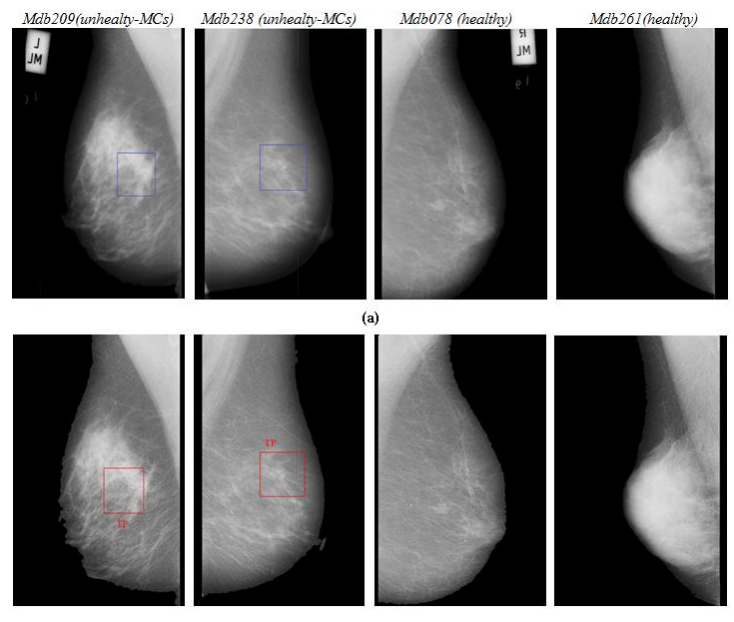

Figure 11. (a) Original mammograms (b) Detection results of the proposed system

Where windows, in original mammograms, show the regions of MC clusters which are defined in the database. Furthermore, as shown in Figure 11, the proposed system gives 0 FP for healthy mammogram examples. In addition to these, we have compared our performance results with the performance results of studies in the literature for detection of MC clusters which are given in Appendices A8.

As observed in Appendices A8, we have the highest number of mammograms used for the study according to the other studies in literature and this increases the reliability of the system. Furthermore, we have obtained quite satisfactory performance results despite of the highest image number.

According to the program outputs and statistical evaluation results, we can say that an effective system has been developed for automatic detection of MC clusters.

\section{Performance Evaluation for Breast Cancer Diagnosis of Detected MC Clusters}

The developed system for breast cancer diagnosis has been tested on test samples (apart from training samples) and all samples have been classified truly. Thus, the performance evaluation results on MC clusters which have been detected automatically in the previous step (24 MC clusters of 28 are truly detected) are given in Appendices A9.

ROC curve and AUC index of the proposed breast cancer diagnosis system on the detected MC clusters using MedCalc software program are given in Figure 12. 


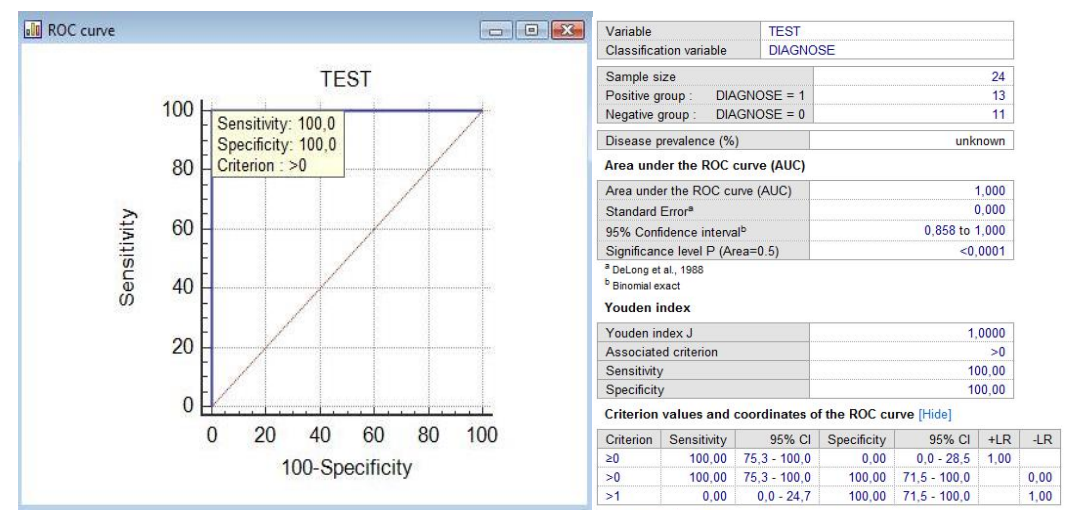

Figure 12. ROC curve and $A U C$ index for the proposed breast cancer diagnosis system

In addition to these, we have compared proposed system with studies in the literature for breast cancer classification of MC clusters which is given in Appendices A10.

As seen in Appendices A10, there are two types of breast cancer diagnosis system for MC clusters. One of them is a whole system which includes detection of MC clusters and benign/malign classification of them (Phadke et al., 2013; Jasmine et al., 2013; Rajesh et al., 2014), and the other one is just includes benign/malign classification of cropped MC region (Strange et al., 2014; Suba et al., 2015). Furthermore, whole systems can be divided into two groups as fully automatic and semi-automatic. In semi-automatic systems, detection process is implemented on manually cropped ROIs. On the other hand, ROI extraction is also automatic in fully automatic systems. Therefore, developing a fully automatic whole system is a very challenging work. In this study, a fully automatic whole system has been developed for MC clusters and obtained very satisfactory results.

\section{CONCLUSION}

In this study, we have developed a novel automatic CAD system for MC clusters. The proposed system produces $98.25 \%$ accuracy and $1.16 \mathrm{FPpI}$ ratio for 23 abnormal (28 MC clusters) and 209 normal images in the MIAS database for detection of MC clusters and 100\% accuracy on 24 detected MC clusters for breast cancer diagnosis. Despite the vision difficulty of MC clusters, the novel system provides very satisfactory results. Furthermore, the developed system is fully automatic whole system which gives outputs as percentages and transformed an assessment categories called PS_BI-RADS inspired from BIRADS approach which has never been used in literature before.

\section{ACKNOWLEDGEMENTS}

The proposed algorithm was used in a developing breast cancer diagnosis system study and supported as a SANTEZ project by the Republic Of Turkey Science, Technology and Industry Ministry and AKGÜN Computer Programs and Services Industry Tic. Ltd. Şti.

\section{REFERENCES}

Albregsten, F., 2008, "Statistical Texture Measures Computed from Gray Level Cooccurrence Matrices", Technical Note, Department of Informatics, University of Oslo.

Bird, R.G., Wallace, T.W., Yankaskas, B.C., 1992, "Analysis of Cancers Missed at Screening Mammography", Radiology, Vol. 184, pp. 613-617.

Bria, A., Karssemeijer, N., Tortorella, F., 2014, "Learning from Unbalanced Data: A Cascade-Based Approach for Detecting Clustered Microcalcifications", Medical Image Analysis, Vol. 18, pp. 241252. 
Chandra, B., Varghese, P.P., 2007, “Applications of Cascade Correlation Neural Networks for Cipher System Identification", International Journal of Computer, Information, Systems and Control Engineering, Vol. 1, No. 2, pp. 343-346.

Cheng, H.D., Shi, X.J., Min, R., Hu, L.M., Cai, X.P., Du, H.N., 2006, “Approaches for Automated Detection and Classification of Masses in Mammograms", Pattern Recognition, Vol. 39, pp. 646 668.

Dennis, J.E., Schnabel, R.B., 1996, Numerical Methods for Unconstrained Optimization and Nonlinear Equations, Siam Press, Philadelphia, A.B.D.

Dheeba, S., Singh, N.A., Selvi, S.T., 2014, “Computer-Aided Detection of Breast Cancer on Mammograms: A Swarm Intelligence Optimized Wavelet Neural Network Approach", Journal of Biomedical Informatics, Vol. 49, pp. 45-52.

Diaz-Huerta, C.C., Felipe-Riveron, E.M., Montaño-Zetina, L.M., 2014, “Quantitative Analysis of Morphological Techniques for Automatic Classification of Micro-Calcifications in Digitized Mammograms", Expert Systems with Applications, Vol. 41, pp. 7361-7369.

Ergen, B., Baykara, M., 2011, “İstatistiksel Uzaysal Alan Metotlarının Içerik Tabanlı Tıbbi Görüntü Erişimi için Bir Uygulama", Fırat University Mühendislik Bilimleri Dergisi, Vol. 23, No. 2, pp. 8793.

Fahlman, S.E., Lebiere, C., "The Cascade-Correlation Learning Architecture", Advances in Neural Information Processing Systems 2, San Francisco, 1990.

Gao, X.Z., Wang, X., Ovaska, S.J., 2009, "Fusion of Clonal Selection Algorithm and Differential Evolution Method in Training Cascade-Correlation Neural Network", Neurocomputing, Vol. 72, pp. 2483-2490.

Halkiotis, S., Botsis, T., Rangoussi, M., 2007, "Automatic Detection of Clustered Microcalcifications in Digital Mammograms Using Mathematical Morphology and Neural Networks", Signal Processing, Vol. 87, pp. 1559-1568.

Haralick, R.M., Shanmugam, K., Dinstein, I., 1973, “Texture Feature for Image Classification", IEEE Transaction on System, Man and Cybernetics, Vol. 3, No. 6, pp. 610-621.

Herwanto, D., Arymurthy, A.M., 2013, “Association Technique Based on Classification for Classifying Microcalcification and Mass in Mammogram", International Journal of Computer Science, Vol. 10, No. 2, pp. 252-259.

Jasmine, J.S.L., Baskaran, S., Govardhan, A.A., 2013, “Robust Approach to Classify Microcalcification in Digital Mammograms Using Contourlet Transform and Support Vector Machine", American Journal of Engineering and Applied Sciences, Vol. 6, No. 1, pp. 57-68.

Jasmine, J.S.L., Govardhan, A., Baskaran, S., "Microcalcification Detection in Digital Mammograms Based on Wavelet Analysis and Neural Networks", International Conference on Control, Automation, Communication and Energy Conservation, Perundurai, 1-6, 4-6 June 2009.

Jelvehfard, E., Faez, K., Laluie, A., 2013, “Microcalcification Detection in Mamography Images Using 2D Wavelet Coefficients Histogram", Computer Science and Information Technology, Vol. 1, No. 3, pp. 178-184.

Karahaliou, A., Skiadopoulos, S., Boniatis, I., Sakellaropoulos, P., Likaki, E., Panayiotakis, G., Costaridou, L., 2007, "Texture Analysis of Tissue Surrounding Microcalcifications on Mammograms for Breast Cancer Diagnosis", The British Journal of Radiology, Vol. 80, pp. 648656.

Kovalishyn, V.V., Tetko, I.V., Luik, A.I., Kholodovych, V.V., Villa, A.E.P., Livingstone, D.J., 1998, "Neural Network Studies. 3. Variable Selection in The Cascade-Correlation Learning Architecture", Journal of Chemical Information and Computer Sciences, Vol. 38, pp. 651-659.

Kurt, B., Nabiyev, V.V., Turhan, K., 2015, “A Novel Algorithm for Segmentation of Suspicious Microcalcification Regions on Mammograms", Lecture Notes in Computer Science, Vol. 9043, pp. 222-230. 
Martins, L.O., Santos, A.M., Silva, A.C., Paiva, A.C., "Classification of Normal, Benign And Malignant Tissues Using Co-Occurrence Matrix and Bayesian Neural Network in Mammographic Images", Proceedings of the 9th Brazilian Symposium on Neural Networks, Ribeirao Preto, 24-29, 2327 October 2006,.

Mazurowskia, M.A., Habasa, P.A., Zuradaa, J.M., Lob, J.Y., Bakerb, J.A., Tourassib, G.D., 2008, “Training Neural Network Classifiers for Medical Decision Making: The Effects of Imbalanced Datasets on Classification Performance", Neural Networks, Vol. 21, pp. 427-436.

Medcalc Statistical Software, http://www.medcalc.org/ ( last modified 2013), last accessed 22 April 2014.

Mohamed, H., Mabrouk, M.S., Sharawy, A., 2014, "Computer Aided Detection System for Micro Calcifications in Digital Mammograms", Computer Methods and Programs in Biomedicine, Vol. 116, pp. 226-235.

Mohanalin, J., Beenamol, M., Kalra, P.K., Kumar, N., 2010, “A Novel Automatic Microcalcification Detection Technique Using Tsallis Entropy \& Type II Fuzzy Index", Computers and Mathematics with Applications, Vol. 60, pp. 2426-2432.

Mohanty, A.K., Beberta, S., Lenka, S.K., 2011, “Classifying Benign and Malignant Mass Using GLCM and GLRLM Based Texture Features From Mammogram", International Journal of Engineering Research and Applications, Vol. 1, pp. 687-693.

Nocedal, G., Wright, S., 2006, Numerical Optimization, Springer, New York, A.B.D.

Pal, N.R., Bhowmick, B., Patel, S.K., Pal, S., Das, J., 2008, “A Multi-Stage Neural Network Aided System for Detection of Microcalcifications in Digitized Mammograms", Neurocomputing, Vol. 71, pp. 2625- 2634.

Phadke, A.C., Rege, P.P., 2013, "Detection and Classification of Microcalcifications Using Discrete Wavelet Transform", International Journal of Emerging Trends\&Technology in Computer Science, Vol. 2, No. 4, pp. 130-134.

Radhakrishnan, M., Kuttiannan, T., 2012, “Comparative Analysis of Feature Extraction Methods for The Classification of Prostate Cancer From TRUS Medical Images", International Journal of Computer Science, Vol. 9, No. 2, pp. 171-179.

Rajesh, A., Ellappan, M., 2014, "Classification of Microcalcification Based on Wave Atom Transform", Journal of Computer Science, Vol. 10, No. 8, pp. 1543-1547.

Rizzi, M., D'Aloia, M., Castagnolo, B., 2012, “Review: Health Care CAD Systems for Breast Microcalcification Cluster Detection", Journal of Medical and Biological Engineering, Vol. 32, No. 3, pp. 147-156.

Sabu, M.A., Ponraj, D.N., Poongodi, R., 2012, “Textural Features Based Breast Cancer Detection: A Survey", Journal of Emerging Trends in Computing and Information Sciences, Vol. 3, No. 9, pp. 1329-1334.

Sharma, N., Om, H., 2014, "Cascade Correlation Neural Network Model for Classification of Oral Cancer", Wseas Transactions on Biology And Biomedicine, Vol. 11, pp. 45-51.

Stewart, B.W., Wild, C.P., 2014, World Cancer Report 2014, World Health Organization Press, Swiss.

Strange, H., Chen, Z., Denton, E.R.E., Zwiggelaar, R., 2014, “Modelling Mammographic Microcalcification Clusters Using Persistent Mereotopology", Pattern Recognition Letters, Vol. 47, pp. 157-163.

Suba, C., Nirmala, K., 2015, "An Automated Classification of Microcalcification Clusters in Mammograms Using Dual Tree M-Band Wavelet Transform and Support Vector Machine", International Journal of Computer Applications, Vol. 115, No. 20, pp. 24-29.

Thangavel, K., Mohideen, A.K., 2009, “Classification of Microcalcifications Using Multi-Dimensional Genetic Association Rule Miner", International Journal of Recent Trends in Engineering, Vol. 2, No. 2, pp. 233-235.

The American College of Radiology (ACR), ACR BI-RADS® Atlas - Mammography, Frequently Asked Questions, https://www.acr.org/-/media/ACR/Files/RADS/BI-RADS/Mammography-FAQ.pdf, last accessed 22 October 2015. 
University of Essec, Mamographic Image Analysis Society, http://peipa.essex.ac.uk/info/mias.html, last accessed 22 December 2014.

Vivona, L., Cascio, D., Fauci, F., Raso, G., 2014, "Fuzzy Technique for Microcalcifications Clustering in Digital Mammograms", BMC Medical Imaging, Vol. 14, No.23, pp. 1-18.

Xu, D., Kurani, A.S., Furst, J.D., Raicu, D.S., "Run-Length Encoding for Volumetric Texture", The IASTED International Conference on Visualization, Imaging, and Image Processing, Marbella, Spain, 131-136, 6-8 September 2004.

Zyout, I., Czajkowska, J., Grzegorzek, M., 2015, “Multi-Scale Textural Feature Extraction and Particle Swarm Optimization Based Model Selection for False Positive Reduction in Mammography", Computirized Medical Imaging and Graphics, Vol. 46, No. 2, pp. 95-107.

\section{Appendix}

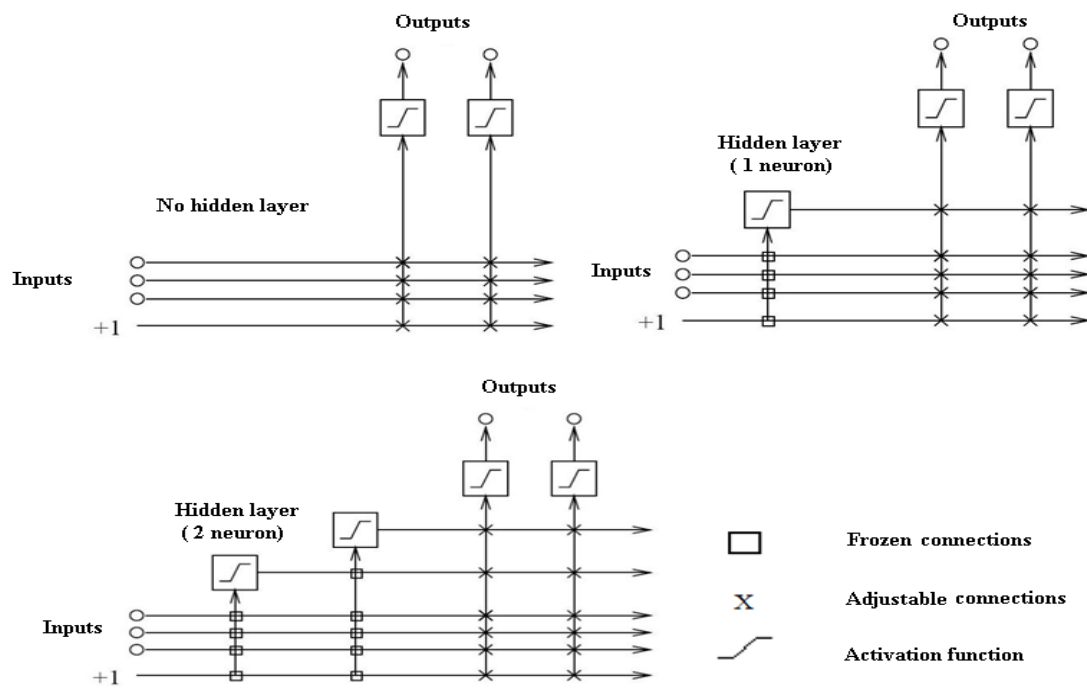

Figure A.1. CCNN architecture

Table A.2. Training performances of the developed CCNN models for FP reduction

\begin{tabular}{cccccccccc}
\hline & \multicolumn{3}{c}{ CCNN_1 } & \multicolumn{3}{c}{ CCNN_2 } & \multicolumn{3}{c}{ CCNN_3 } \\
\hline Total & MC ROIs & FP ROIs & All & MC ROIs & FP ROIs & All & MC ROIs & FP ROIs & All \\
Correct & 14 & 30 & 44 & 14 & 30 & 44 & 14 & 30 & 44 \\
Incorrect & 12 & 27 & 39 & 9 & 27 & 36 & 10 & 27 & 37 \\
$\begin{array}{c}\text { Training } \\
\text { Performance }\end{array}$ & $\%$ & 3 & 5 & 5 & 3 & 8 & 4 & 3 & 7 \\
\hline
\end{tabular}

Table A.3. The parameters of CCNN models

\begin{tabular}{ccccccc}
\hline Model & $\begin{array}{c}\text { Kernel function for hidden } \\
\text { layer }\end{array}$ & \multicolumn{3}{c}{ Parameters } \\
& & Hidden layer \\
& neuron number & $\begin{array}{c}\text { Weights for the } \\
\text { hidden layer } \\
\text { Min. }\end{array}$ & $\begin{array}{c}\text { Weights for the } \\
\text { output layer } \\
\text { Min. } \\
\text { Max. }\end{array}$ \\
CCNN_1 & Gauss & 3 & -7.156 & 34.722 & -6.687 & 5.822 \\
CCNN_2 & Sigmoid & 1 & -105.541 & 93.643 & -7.227 & 8.602 \\
CCNN_3 & Sigmoid\&Gauss & 2 & -9.066 & 13.08 & -10.471 & 11.628 \\
\hline
\end{tabular}


Table A.4. BI-RADS assessment categories

\begin{tabular}{|c|c|c|}
\hline BI-RADS $^{\oplus}$ Assessment Category & $\begin{array}{c}\text { BI-RADS }^{\ominus} \\
\text { Numeric Code }\end{array}$ & FDA-Approved Equivalent Wording \\
\hline Incomplete & 0 & $\begin{array}{l}\text { Incomplete Mammogram: Need Additional } \\
\text { Imaging Evaluation }\end{array}$ \\
\hline Negative & 1 & Negative Mammogram \\
\hline Benign & 2 & Benign Abnormality \\
\hline Probably Benign & 3 & Probably Benign Abnormality \\
\hline Suspicious & 4 & $\begin{array}{l}\text { Suspicious Abnormality - Biopsy Should Be } \\
\text { Considered }\end{array}$ \\
\hline Highly Suggestive of Malignancy & 5 & Highly Suggestive for Malignancy \\
\hline Known Biopsy-Proven Malignancy & 6 & $\begin{array}{l}\text { Known Biopsy-Proven Cancer } \\
\text { Known Malignancy }\end{array}$ \\
\hline
\end{tabular}

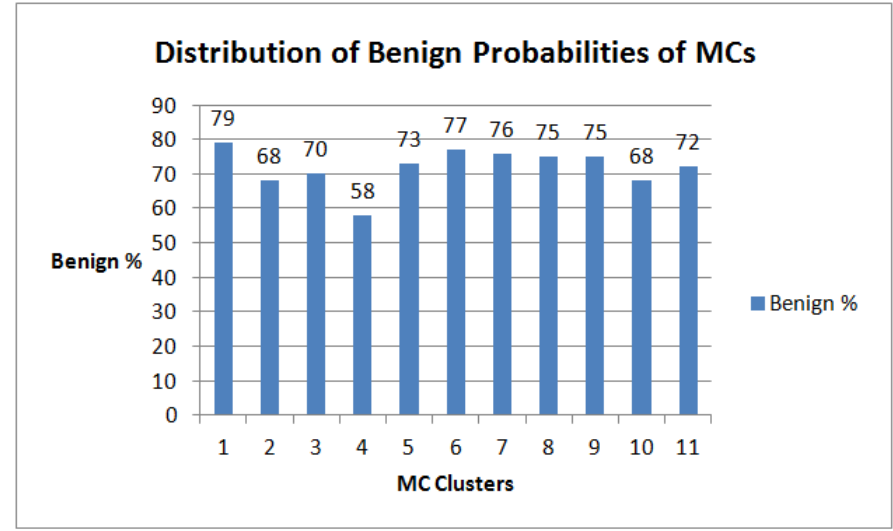

(a)

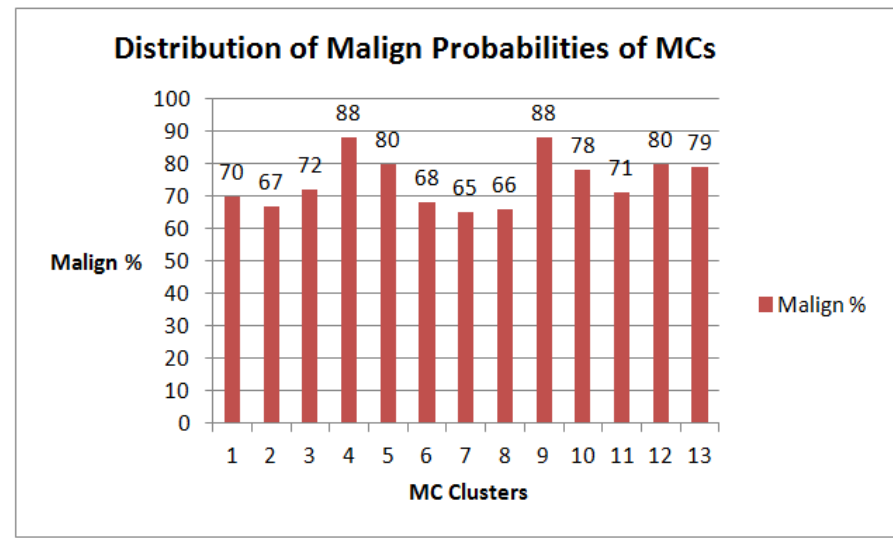

(b)

Figure A.5. The distributions of (a) benign and (b) malign probabilities of MC clusters

Table A.6. Comparison results of the developed detection system

\begin{tabular}{cccccc}
\hline & \multicolumn{3}{c}{ Normal } & \multicolumn{3}{c}{ MCs } \\
\cline { 2 - 6 } ROIs & TP & 209 & FP & TN & FN \\
& 28 & 15715 & - & 0 \\
Classification with ANN & 24 & 1107 & 14608 & 4 \\
$\begin{array}{c}\text { Classification with ANN and FP reduction } \\
\text { with CCNN }\end{array}$ & 24 & 270 & 15445 & 4 \\
\hline
\end{tabular}




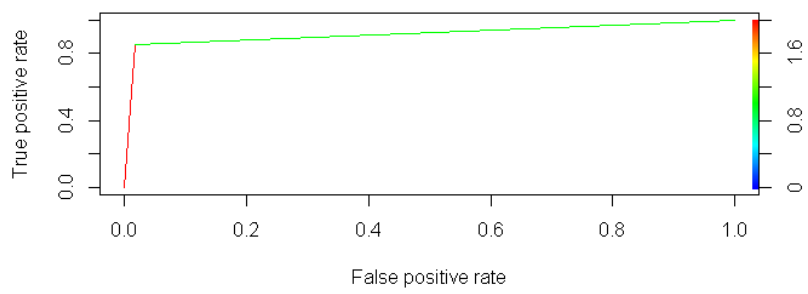

(a)

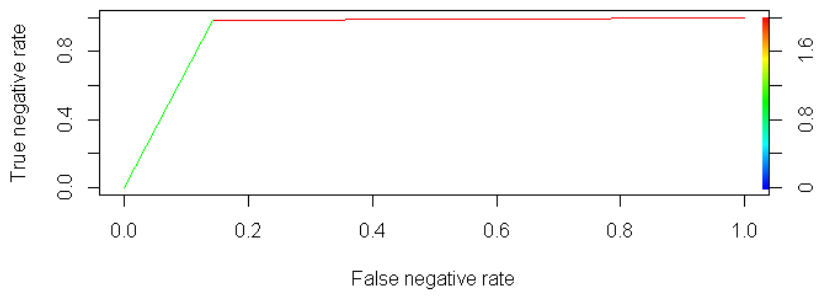

(b)

Figure A.7. The graphics of (a) TPR with FPR and (b) TNR with FNR

Table A.8. Comparison results of the proposed algorithm with studies in the literature for detection of MC clusters

\begin{tabular}{|c|c|c|c|c|c|}
\hline Methods & Database & $\begin{array}{c}\text { Sensitivty } \\
(\%)\end{array}$ & $\begin{array}{c}\text { Specificity } \\
(\%)\end{array}$ & $\begin{array}{c}\text { Accuracy } \\
(\%)\end{array}$ & $F P p I$ \\
\hline $\begin{array}{c}\text { Anuradha et al., } 2013 \\
\text { Wavelet transform based features } \\
S V M \\
A N N\end{array}$ & $\begin{array}{l}\text { MIAS } \\
49 \text { Mammograms } \\
\text { (23 MC }-26 \text { normal) }\end{array}$ & $\begin{array}{r}75.6 \\
98.08\end{array}$ & $\begin{array}{c}81.25 \\
100\end{array}$ & $\begin{array}{l}79.58 \\
99.04\end{array}$ & - \\
\hline $\begin{array}{c}\text { Jelvehfard et al., } 2013 \\
\text { Wavelet transform based features } \\
S V M\end{array}$ & $\begin{array}{c}\text { MIAS } \\
49 \text { Mammograms } \\
\text { (23 MC }-26 \text { normal) }\end{array}$ & 88.11 & 92 & - & - \\
\hline $\begin{array}{c}\text { Halkiotis et al., } 2007 \\
\text { Mathematical morphology based features ANN }\end{array}$ & $\begin{array}{l}\text { MIAS } \\
\text { 53 Mammograms } \\
(23 \mathrm{MC}-30 \text { normal })\end{array}$ & 94.70 & - & - & 0.27 \\
\hline $\begin{array}{l}\text { Vivona et al., } \mathbf{2 0 1 4} \\
\text { Shape and grey level based features } \\
\text { Fuzzy clustering }\end{array}$ & $\begin{array}{c}\text { MIAS } \\
20 \text { Mammograms } \\
(20 \mathrm{MC})\end{array}$ & 82 & - & 94 & 4 \\
\hline $\begin{array}{c}\text { Mohanalin et al., } 2010 \\
\text { Tsallis entropy \& fuzzy based enhancement with } \\
\text { iterative thresholding }\end{array}$ & $\begin{array}{c}\text { MIAS } \\
41 \text { Mammograms } \\
\text { (23 MC }-18 \text { normal) }\end{array}$ & 93.75 & - & - & 0.52 \\
\hline $\begin{array}{c}\text { Diaz-Huerta et al., } 2014 \\
\text { Spatial, spectral and textural features } \\
S V M\end{array}$ & $\begin{array}{l}\text { MПAS } \\
22 \text { Mammograms } \\
(22 \mathrm{MC})\end{array}$ & 86.6 & 84.36 & - & 1.77 \\
\hline $\begin{array}{c}\text { Proposed Algorithm } \\
\text { GLCM \& ANN (Classification of MC ROIs) } \\
\text { GLRLM \& CCNN (FP reduction) }\end{array}$ & $\begin{array}{c}\text { MIAS } \\
\text { 232 Mammograms } \\
\text { (23 MC -209 normal) }\end{array}$ & 85.7 & 98.3 & 98.25 & 1.163 \\
\hline
\end{tabular}


Table A.9. Classification results of the proposed benign/malign classification algorithm

\begin{tabular}{cccc}
\hline & $\begin{array}{c}\text { Detected MC } \\
\text { Clusters }\end{array}$ & $\begin{array}{c}\text { Benign/Malign True } \\
\text { Classification Result }\end{array}$ & $\%$ \\
\hline Benign & 11 & 11 & 100 \\
Malign & 13 & 13 & 100 \\
Total & 24 & 24 & 100 \\
\hline
\end{tabular}

Table A.10. Comparison results of the proposed system with studies in the literature for breast cancer diagnosis of MC clusters

\begin{tabular}{|c|c|c|c|c|c|}
\hline Methods & Database & $\begin{array}{l}\text { Sensitivity } \\
(\%)\end{array}$ & $\begin{array}{c}\text { Specificity } \\
(\%)\end{array}$ & Accuracy & System Information \\
\hline \multicolumn{5}{|l|}{ Phadke et al., 2013} & \multirow{2}{*}{$\begin{array}{c}\text { Whole system } \\
\text { (detection\&classification) }\end{array}$} \\
\hline Wavelet transform based & MIAS & & & & \\
\hline features & 15 Benign -11 Malign & 65.16 & 76.67 & 69.30 & \multirow{2}{*}{$\begin{array}{c}\text { Semi-automatic detection } \\
\text { (detection from manually } \\
\text { cropped ROI image) }\end{array}$} \\
\hline $\begin{array}{l}S V M \\
A N N\end{array}$ & $\mathrm{MCs}$ & 95.45 & 96.66 & 96.15 & \\
\hline \multirow{5}{*}{$\begin{array}{c}\text { Strange et al., } 2014 \\
\text { A multi-scale topological } \\
\text { approach } \\
\text { A nearest neighbour based } \\
\text { strategy }\end{array}$} & \multirow{5}{*}{$\begin{array}{r}\text { MIAS } \\
11 \text { Benign }-10 \\
\text { MCs }\end{array}$} & \multirow{5}{*}{100} & \multirow{5}{*}{91} & \multirow{5}{*}{95} & \multirow{5}{*}{$\begin{array}{l}\text { Classification system } \\
\text { (benign/malign } \\
\text { classification from } \\
\text { manually cropped MC } \\
\text { ROI) }\end{array}$} \\
\hline & & & & & \\
\hline & & & & & \\
\hline & & & & & \\
\hline & & & & & \\
\hline \multirow{5}{*}{$\begin{array}{l}\text { Suba et al., } 2015 \\
\text { Dual Tree M-Band } \\
\text { Wavelet Transform } \\
\text { (DTMBWT) } \\
\text { SVM }\end{array}$} & \multirow{5}{*}{$\begin{array}{c}\text { MIAS } \\
12 \text { Benign -13 Malign } \\
\text { MCs }\end{array}$} & \multirow{5}{*}{89.33} & \multirow{5}{*}{94.33} & \multirow{5}{*}{91.83} & Classification system \\
\hline & & & & & (benign/malign \\
\hline & & & & & classification from \\
\hline & & & & & manually cropped MC \\
\hline & & & & & ROI) \\
\hline Jasmine et al., 2013 & & & & & \multirow{3}{*}{$\begin{array}{c}\text { Whole system } \\
\text { (detection\&classification) } \\
\text { Semi-automatic detection } \\
\text { (detection from manually } \\
\text { cropped ROI image) }\end{array}$} \\
\hline Nonsubsampled Contourlet & MIAS & & & & \\
\hline $\begin{array}{l}\text { Iransform (NOST) } \\
\qquad S V M\end{array}$ & $\begin{array}{c}12 \text { Benign }-13 \text { Malign } \\
\text { MCs }\end{array}$ & 92.3 & 100 & 96.15 & \\
\hline \multirow{4}{*}{$\begin{array}{l}\text { Rajesh et al., } 2014 \\
\text { Wave Atom Transform } \\
\qquad \begin{array}{c}\text { (WAT) } \\
\text { SVM }\end{array}\end{array}$} & \multirow{4}{*}{$\begin{array}{c}\text { MIAS } \\
12 \text { Benign }-13 \text { Malign } \\
\text { MCs }\end{array}$} & \multirow{4}{*}{100} & \multirow{4}{*}{100} & \multirow{4}{*}{100} & \multirow{4}{*}{$\begin{array}{c}\text { Whole system } \\
\text { (detection\&classification) } \\
\text { Semi-automatic detection } \\
\text { (detection from manually } \\
\text { cropped ROI image) }\end{array}$} \\
\hline & & & & & \\
\hline & & & & & \\
\hline & & & & & \\
\hline \multirow{4}{*}{$\begin{array}{l}\text { Proposed Algorithm } \\
\text { GLCM, Statistical, } \\
\text { GLRLM based features } \\
\text { DA\&SVM }\end{array}$} & \multirow{4}{*}{$\begin{array}{c}\text { MIAS } \\
11 \text { Benign -13 Malign } \\
\text { MCs }\end{array}$} & & & & Whole system \\
\hline & & 100 & 100 & 100 & (detection\&classification) \\
\hline & & 100 & 100 & 100 & Fully Automatic \\
\hline & & & & & detection \\
\hline
\end{tabular}

